\title{
Corrosion Behavior of Mg-Al/TiC Composites in NaCl Solution
}

\author{
L. A. Falcon, ${ }^{1}$ E. Bedolla B., ${ }^{1}$ J. Lemus, ${ }^{1}$ C. Leon, ${ }^{1}$ I. Rosales, ${ }^{2}$ \\ and J. G. Gonzalez-Rodriguez ${ }^{2}$ \\ ${ }^{1}$ Instituto de Investigaciones Metalurgicas, Universidad Michoacana de San Nicolás de Hidalgo, 58060 Morelia, MICH, Mexico \\ ${ }^{2}$ CIICAp, Universidad Autonoma del Estado de Morelos, Avenue Universidad 1001, 62209 Cuernevaca, MOR, Mexico
}

Correspondence should be addressed to J. G. Gonzalez-Rodriguez, ggonzalez@uaem.mx

Received 6 October 2010; Revised 14 January 2011; Accepted 17 January 2011

Academic Editor: Sebastian Feliu

Copyright (C) 2011 L. A. Franco et al. This is an open access article distributed under the Creative Commons Attribution License, which permits unrestricted use, distribution, and reproduction in any medium, provided the original work is properly cited.

\begin{abstract}
The corrosion behavior of $\mathrm{TiC}$ particles reinforced $\mathrm{Mg}-\mathrm{Al}$ alloy in 3.5\% $\mathrm{NaCl}$ solution has been evaluated using electrochemical techniques. Tested alloys included an Mg-9Al (Mg AZ91E) alloy with and without 56 wt. \% TiC particles. Electrochemical techniques included potentiodynamic polarization curves, linear polarization resistance, electrochemical noise, and electrochemical impedance spectroscopy measurements. All techniques showed that the composite exhibited a lower corrosion rate than the base alloy. Evidence of galvanic effects that increased the composite corrosion rate was found between the matrix and the TiC particles. Additionally, the tendency to suffer from pitting corrosion was higher for the base alloy than that for the composite. Electrochemical impedance results showed the importance of adsorption/diffusion phenomena in both materials.
\end{abstract}

\section{Introduction}

Nowadays, aluminum matrixes are widely used in metallic matrix composites (MMCs), because they have the highest priority in applications where a combination of corrosion resistance, low density, and high mechanical performance are required, such as in the automotive and aerospace industry. The reinforcement of an aluminum matrix, based on the use of TiC particles is interesting because of its good wettability $[1,2]$ which results in a clean and strong interface [24]. While aluminum alloys are the most commonly used matrix in metal-ceramic composites, it has been reported that the addition of $\mathrm{TiC}$, as reinforcement, improves the mechanical properties at room and high temperatures. However, research in new systems is required due to rapid increase in technological development. Therefore, it could be appreciated as an increasing interest in the use of magnesium and its alloys as a metallic matrix for MMC composites. The main disadvantage of magnesium is the high chemical reactivity due to its negative electrochemical potential; this greatly restricts its industrial applications, and the same disadvantage has been found for $\mathrm{Mg}-\mathrm{Al}-\mathrm{Zn}$ alloys, being $\mathrm{Mg}$ AZ91, the most significant alloy.

Researches on metallic-based matrix composites using magnesium are considerable fewer than those done for aluminum [5-10]. Many studies have been carried out to determine the $\mathrm{Mg}-\mathrm{Al}-\mathrm{Zn}$ corrosion behavior. Pardo et al. [11] concluded that corrosion damage was mainly caused by formation of a $\mathrm{Mg}(\mathrm{OH})_{2}$ corrosion layer. AZ80 and AZ91D alloys revealed the highest corrosion resistance. The relatively fine $\beta$-phase $\left(\mathrm{Mg}_{17} \mathrm{Al}_{12}\right)$ network and the aluminum enrichment produced on the corroded surface were the key factors limiting progression of the corrosion attack. Preferential attack was located at the matrix/ $\beta$-phase and matrix/MnAl intermetallic compounds interfaces. Nunez-Lopez et al. [12] reported the corrosion behavior of Mg ZC71 composites with 12 vol. \% SiC, by electrochemical and saline dew tests. MMC composite showed a 10 times difference in corrosion rates than the alloy. Local corrosion was 3 times faster in the composite than in the monolithic alloy. Furthermore, Nunez observed that there was no correlation between the interface and the local corrosion. Suqiu et al. [13] reported 
the corrosion resistance in Mg AZ91/TiC composites. They observed that the local corrosion rate was higher in the composite due the formation of a thinner layer of corrosion products than in the monolithic alloy. Tiwari et al. [14] studied the corrosion behavior of two SiC Mg-based MMC, namely, Mg-6SiC and Mg-16SiC (vol. \%) in aerated $1 \mathrm{M} \mathrm{NaCl}$ and compared them with the corrosion rate of pure $\mathrm{Mg}$. The presence of $\mathrm{SiC}$ particles deteriorated the corrosion resistance of magnesium, and the corrosion resistance decreased with increasing $\mathrm{SiC}$ volume fraction, finding that galvanic corrosion between $\mathrm{Mg}$ matrix and $\mathrm{SiC}$ reinforcement did not significantly contribute to the overall corrosion rate. Salman et al. [15] carried out a comparative electrochemical study of AZ31 and AZ91 magnesium alloys in $1 \mathrm{M} \mathrm{NaOH}$ and 3.5 wt. $\% \mathrm{NaCl}$ solutions at room temperature. In $1 \mathrm{M}$ $\mathrm{NaOH}$ solution, AZ31 alloy showed several potential drops throughout the experiment but AZ91 alloy did not. When anodized at $3 \mathrm{~V}$ for 30 minutes in $1 \mathrm{M} \mathrm{NaOH}$ solution, the anticorrosion behavior of anodized specimens was better than those of specimens which were not anodized. Finally, Budruk Abhijeet et al. [16] studied the corrosion behavior of pure magnesium, $\mathrm{Mg}-\mathrm{Cu}(0.3,0.6$ and 1 vol. \%) and $\mathrm{Mg}-\mathrm{Mo}(0.1,0.3$ and 0.6 vol. \%) composites in $3.5 \% \mathrm{NaCl}$ solution, finding that the corrosion rate increased with increasing the volume fraction of reinforcement in both composites. At the same volume fraction of reinforcement, molybdenum reinforced composites corroded faster than copper reinforced composites. Microscopic observations of corroded specimens confirmed microgalvanic activity at the matrix/reinforcement interfaces, which, together with a poor quality of corrosion surface films, were responsible for the poor corrosion resistance of composites. Thus, the goal of this research work is to study the effect of $\mathrm{TiC}$ reinforcing particles on the corrosion resistance of an $\mathrm{Mg}-\mathrm{Al}$ alloy in $3.5 \% \mathrm{NaCl}$ solution.

\section{Experimental Procedure}

Chemical composition of tested $\mathrm{Mg}-\mathrm{Al}$ alloy is given on Table 1, where it can be seen that it contains $\mathrm{Mn}$ and $\mathrm{Zn}$ also as main alloying elements, corresponding to an AZ91E alloy. Composites were fabricated by pressureless melt infiltration of the AZ91E alloy into $44 \% \mathrm{TiC}$ porous performs. The average $\mathrm{TiC}$ particles size was $1.12 \mu \mathrm{m}$. These powders were sintered in an argon atmosphere at $1250^{\circ} \mathrm{C}$ during 60 minutes, whereas infiltration was carried out at $950^{\circ} \mathrm{C}$ in an argon atmosphere during 12 minutes. For the corrosion tests, a $3.5 \% \mathrm{NaCl}$ solution was used at room temperature $\left(\approx 25^{\circ} \mathrm{C}\right)$. Polarization curves were recorded at a constant sweep rate of $1 \mathrm{mV} \mathrm{s}^{-1}$ from -800 to $+800 \mathrm{mV}$ interval respect to open circuit potential $\left(E_{\text {corr }}\right)$. A conventional three electrodes glass cell was used with a graphite rod as auxiliary electrode and a saturated calomel electrode (SCE) as reference. Corrosion current density values, $I_{\text {corr }}$, were calculated by using the Tafel extrapolation method and by taking an extrapolation interval of $\pm 250 \mathrm{mV}$ around the $E_{\text {corr }}$ value once stable. Linear polarization resistance, LPR, measurements were carried out by polarizing the specimen from +10 to $-10 \mathrm{mV}$ in respect to $E_{\text {corr }}$, at a scanning rate of $1 \mathrm{mV} \mathrm{s}^{-1}$ every 60 minutes during 24 hours. Electrochemical impedance spectroscopy tests were carried out at $E_{\text {corr }}$ by using a signal with an amplitude of $10 \mathrm{mV}$ and a frequency interval of $0.1 \mathrm{~Hz}-10 \mathrm{kHz}$. An ACM potentiostat controlled by a desktop computer was used for the LPR tests and polarization curves, whereas for the EIS measurements, a model PC4 300 Gamry potentiostat was used. Finally, electrochemical noise measurements (EN) in both current and potential were recorded using two identical working electrodes and a reference electrode (SCE). The electrochemical noise measurements were made recording simultaneously the potential and current fluctuations at a sampling rate of 1 point per second during a period of 1024 seconds. Removal of the DC trend from the raw noise data was the first step in the noise analysis when needed. To accomplish this, a least square fitting method was used. Finally, the noise resistance, $R_{n}$, was then calculated as the ratio of the potential noise standard deviation, $\sigma_{v}$, over the current noise standard deviation, $\sigma_{i}$, according to:

$$
R_{n}=\frac{\sigma_{v}}{\sigma_{i}}
$$

where $R_{n}$ can be taken as the linear polarization resistance, $R_{p}$ in the Stern-Geary equation

$$
I_{\text {corr }}=\frac{b_{a} \cdot b_{c} \cdot 1}{2.23\left(b_{a}+b_{c}\right) R_{p}}
$$

and thus, inversely proportional to the corrosion rate, $I_{\text {corr }}$.

\section{Results}

The resulting microstructures of both the AZ91E alloy and AZ91E/TiC composite are shown on Figure 1. The surface image obtained by SEM of a polished sample of AZ91E alloy can be observed in Figure 1(a). It was not possible to observe the grain boundaries, however, the primary $\alpha$ $\mathrm{Mg}$ phase, together with an eutectic phase aluminum rich surrounding the $\beta$ phase constituted of $\mathrm{Al}_{12} \mathrm{Mg}_{17}$ could be observed. Additionally, a few AlMn-base precipitates could be observed along the matrix area. Less than 30\% in fraction area correspond to the eutectic phase, while that approximately a $60 \%$ it is occupied by the primary phase. Figure 1(b) shows the composite surface distribution of the AZ91E/TiC composite, where the particles reinforcement of $\mathrm{TiC}$ are visible with approximately $50 \%$ area fraction with an average size of $1.5 \mu \mathrm{m}$. In the image, the dark zones correspond to a porosity distributed on the surface and the small particles correspond to the MgAZ91E matrix with an average size of $1.0 \mu \mathrm{m}$. It was observed that the $\mathrm{TiC}$ particles did not present a good enough cohesion with the alloy, which might produce a depletion of the particles from the matrix.

Polarization curves for the AZ91E alloy and AZ91E/TiC composite in the $3.5 \% \mathrm{NaCl}$ solution is shown on Figure 2. These curves showed an active behavior only, without any passive zone, instead, an anodic limiting current was observed, with values of 6.11 and $0.16 \mathrm{~A} / \mathrm{cm}^{2}$ for AZ91E alloy and AZ91E/TiC composite, respectively. The $E_{\text {corr }}$ value was more active for the base alloy, close to $-1390 \mathrm{mV}$, 

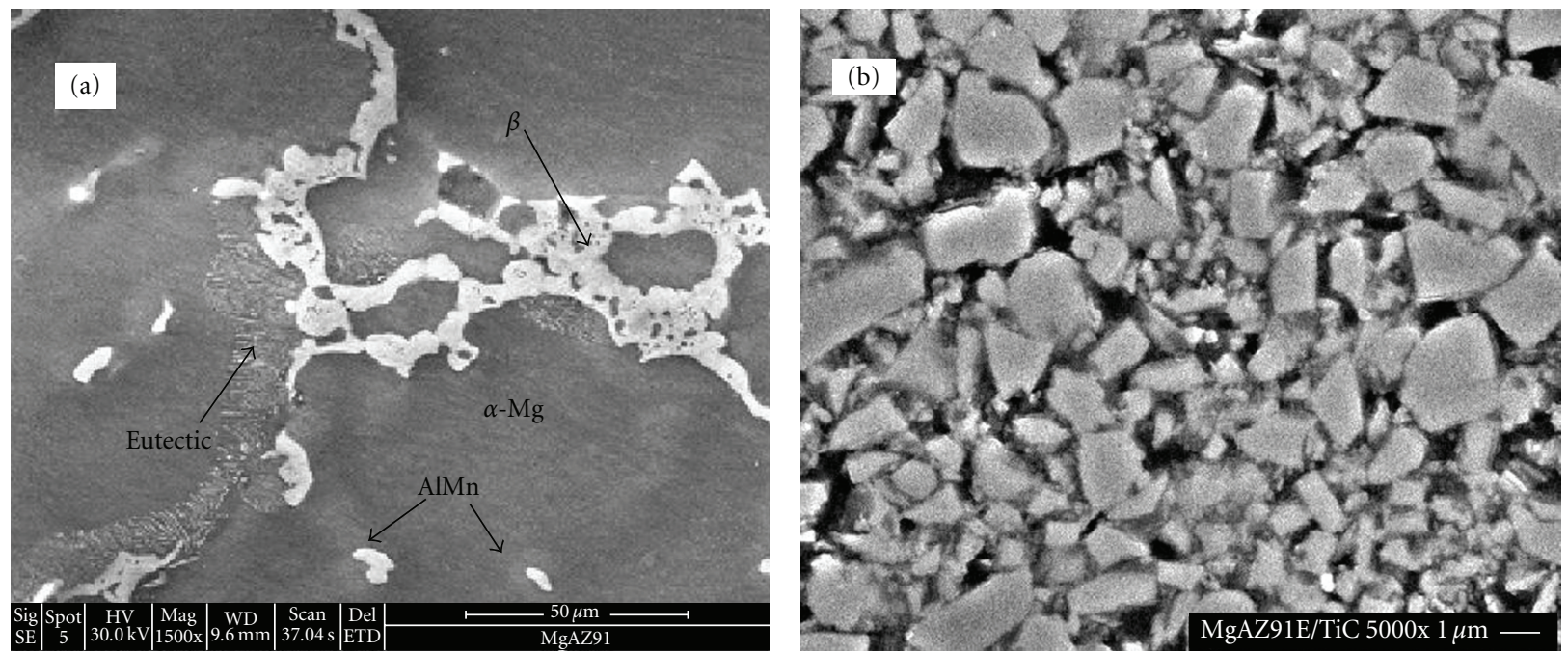

FIGURE 1: SEM micrograph of AZ91E alloy and AZ91E/TiC composite.

TABLE 1: Chemical composition of tested AZ91E alloy.

\begin{tabular}{lllllllll}
\hline Element & $\mathrm{Al}$ & $\mathrm{Mn}$ & $\mathrm{Zn}$ & $\mathrm{Si}$ & $\mathrm{Fe}$ & $\mathrm{Cu}$ & $\mathrm{Ni}$ & $\mathrm{Mg}$ \\
\hline wt. $\%$ & 8.7 & 0.24 & 0.7 & 0.20 & 0.005 & 0.015 & 0.001 & Bal. \\
\hline
\end{tabular}

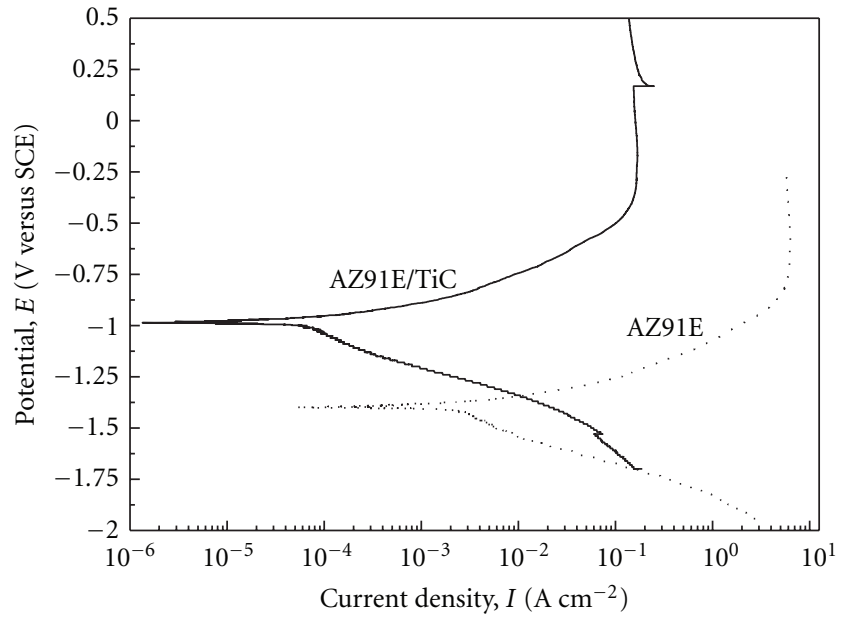

Figure 2: Polarization curves for AZ91E alloy and AZ91E/TiC composite in $3.5 \% \mathrm{NaCl}$ solution.

than that for composite, which had a value of $-980 \mathrm{mV}$. The corrosion current density value was also lower for the composite, $8.8 \times 10^{-5} \mathrm{~A} \mathrm{~cm}^{-2}$, than that for the base alloy, $2.9 \times 10^{-3} \mathrm{~A} \mathrm{~cm}^{-2}$.The change in the $E_{\text {corr }}$ value with time, Figure 3, shows that at all times, the base alloy kept more active values than those for the composite, although the later had a tendency towards nobler values. The change in the $R_{p}$ value with time for both the base metal and composite is given on Figure 4, where it can be seen that the AZ91E base alloy showed lower $R_{p}$ values, and thus, higher corrosion rates, than the $\mathrm{AZ91E/TiC} \mathrm{composite.} \mathrm{However,} \mathrm{the} R_{p}$ value

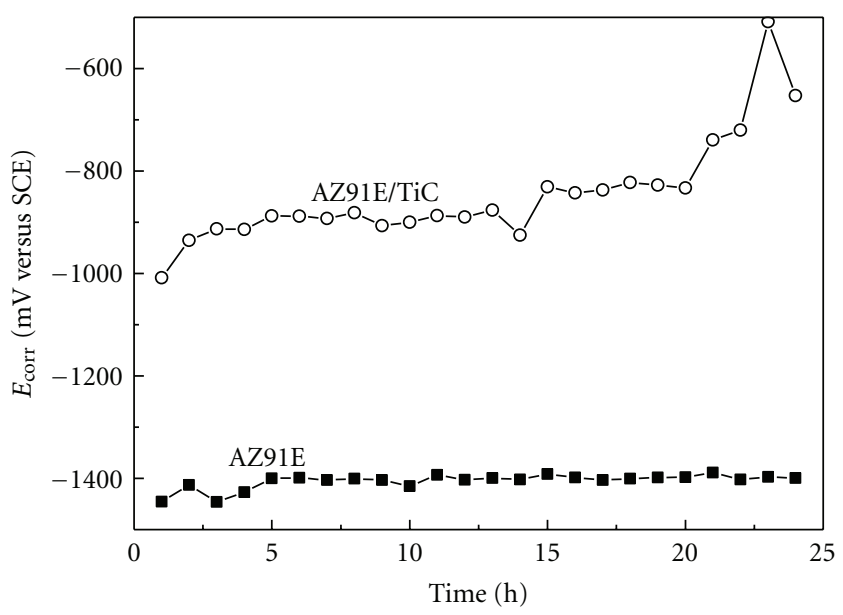

Figure 3: Change in the $E_{\text {corr }}$ value with time for AZ91E alloy and AZ91E/TiC composite in $3.5 \% \mathrm{NaCl}$ solution.

for the AZ91E base alloy showed a tendency to increase and, after that, to decrease as time elapsed, and, thus, the corrosion rate decreases first and after that it increases, indicating the cracking or detachment of any protective corrosion products layer, showing the nonprotective nature of this layer. It could be also due to the fact that the Al12Mg17 particles enhance the dissolution of the $\alpha-\mathrm{Mg}$ phase since it is cathode as compared to the matrix.

Nyquist diagrams for the base alloy, Figure 5, showed a capacitive semicircle at high frequencies, but at lower or intermediate frequencies, the data described a straight line, indicating that the corrosion process is under a mixed 
TABLE 2: Electrochemical parameters obtained from polarization curves.

\begin{tabular}{lccccc}
\hline Alloy & $E_{\text {corr }}(\mathrm{mV})$ & $I_{\text {corr }}\left(\mathrm{A} \mathrm{cm}^{-2}\right)$ & $\beta_{\mathrm{a}}(\mathrm{mV} / \mathrm{dec})$ & $\beta_{\mathrm{c}} /(\mathrm{mV} / \mathrm{dec})$ & Anodic limit current $\left(\mathrm{Acm}^{-2}\right)$ \\
\hline AZ91E/TiC & -980 & $8.8 \times 10^{-5}$ & 170 & 187 & 0.16 \\
AZ91E & -1390 & $2.9 \times 10^{-3}$ & 155 & 177 & 6.11 \\
\hline
\end{tabular}

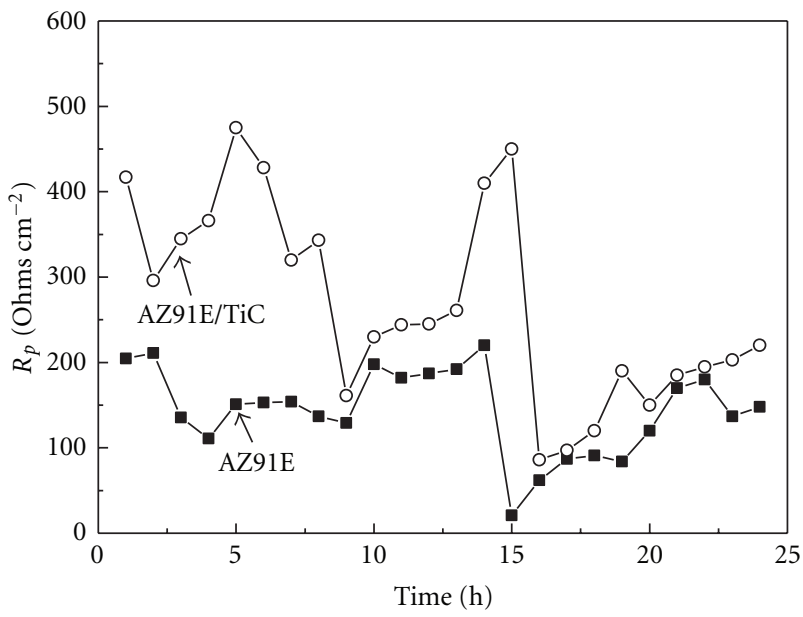

FIgure 4: Change in the $R_{p}$ value with time for AZ91E alloy and AZ91E/TiC composite in $3.5 \% \mathrm{NaCl}$ solution.

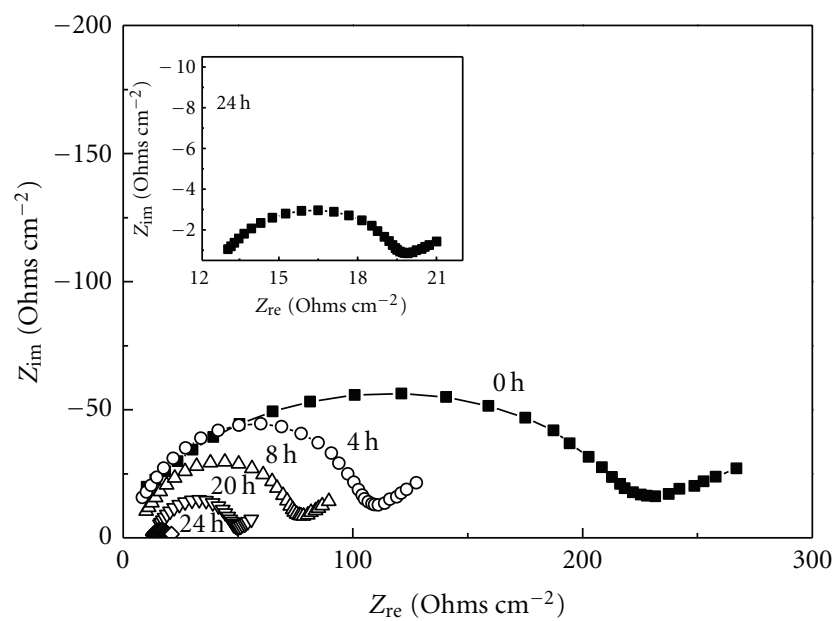

Figure 5: Change in the Nyquist diagrams with time for AZ91E alloy in $3.5 \% \mathrm{NaCl}$ solution.

mechanism: charge transfer from the metal to the interface through the double electrochemical layer, and by the diffusion of aggressive ions through the corrosion products layer, such as evidenced by polarization curves shown on Figure 2. This diffusion phenomena are the responsible of the anodic limit current observed on the polarization curve, Figure 2. The diameter of the high frequency capacitive semicircle, described as the charge transfer resistance, $R_{\mathrm{ct}}$, equivalent to the polarization resistance, $R_{p}$, in (2) decreased as time elapsed, with an increase in the corrosion rate with time. This decrease in the $R_{\mathrm{ct}}$ value as time increases is similar to the decrease in the $R_{p}$ value shown in Figure 4 . On the

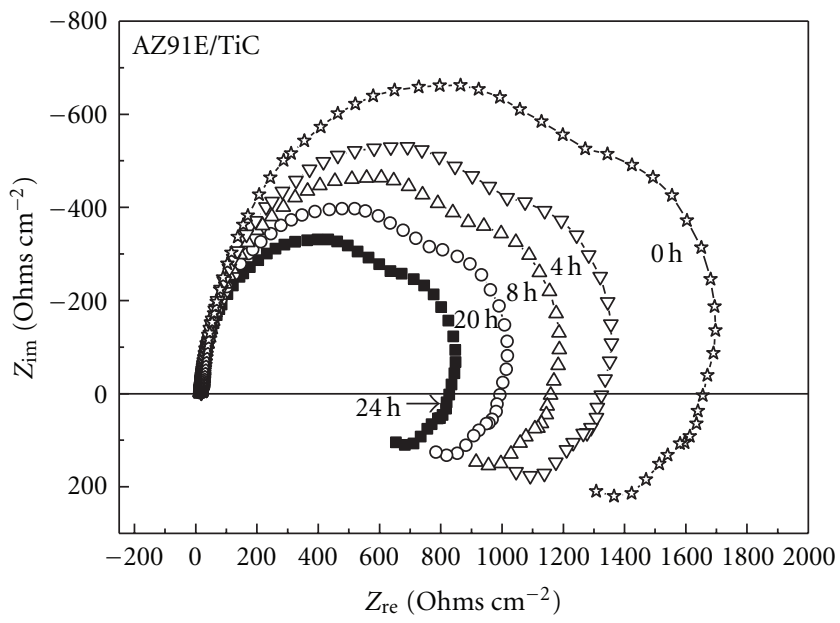

FIgure 6: Change in the Nyquist diagrams with time for AZ91E/TiC composite in $3.5 \% \mathrm{NaCl}$ solution.

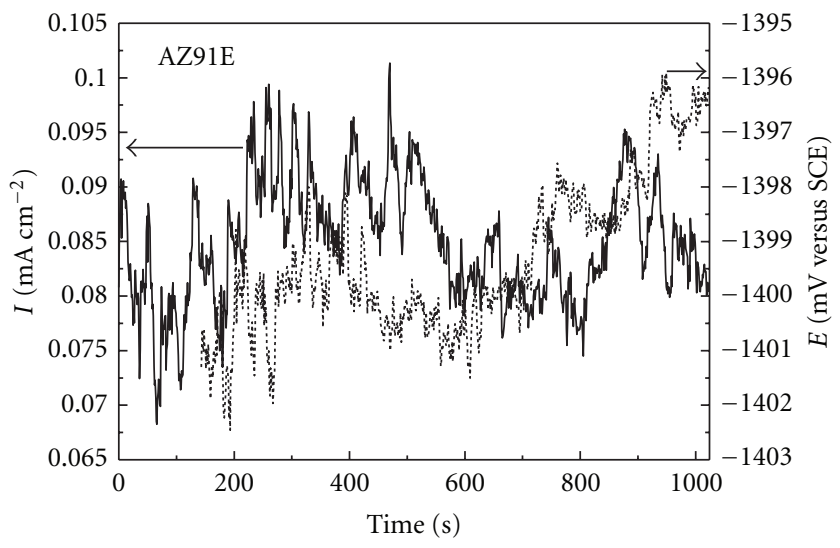

Figure 7: Noise in current and potential for AZ91E alloy in 3.5\% $\mathrm{NaCl}$ solution.

other hand, Nyquist diagrams for AZ91E/TiC composite, Figure 6, showed a capacitive-like, depressed semicircle at high frequencies, followed by an inductive loop at low and intermediate frequencies, indicating that the corrosion process is under control of adsorption of chloride ions at the metal/solution interface. The diameter of the semicircles decreased as time elapsed, indicating an increase in the corrosion rate with time and the nonprotective nature of the corrosion products.

The time series in both potential and in current for the AZ91E base alloy is shown on Figure 7, where it can be seen that in both cases, the time series showed transients in high intensity or amplitude, with a sudden decrease in their values. Each transient represents the rupture of the corrosion 


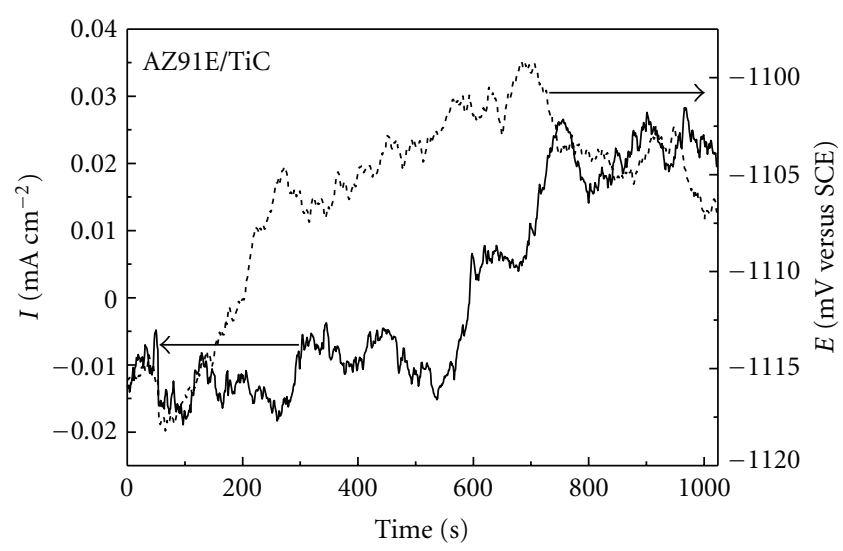

FIgUre 8: Noise in current and potential for AZ91E/TiC composite in $3.5 \% \mathrm{NaCl}$ solution.

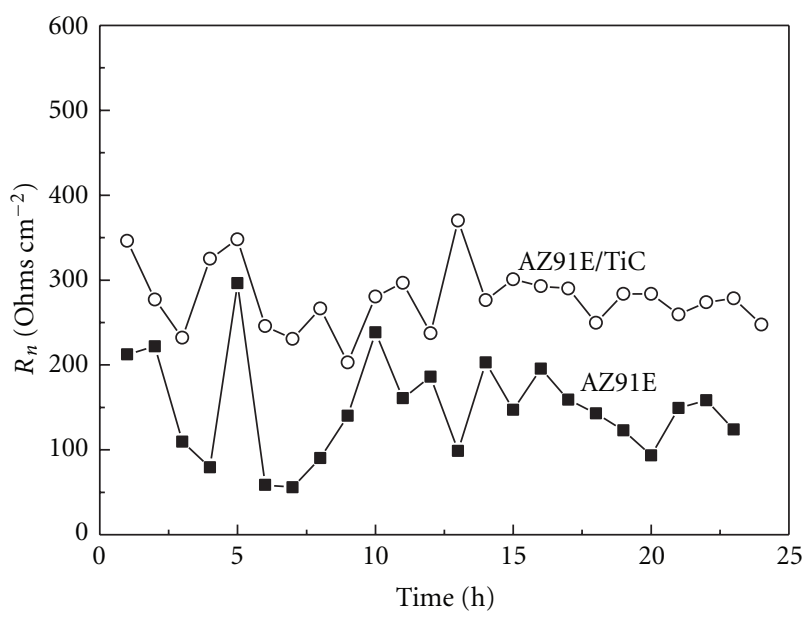

FIGURE 9: Change in the noise resistance value, $R_{n}$, with time for AZ91E alloy and AZ91E/TiC composite in $3.5 \% \mathrm{NaCl}$ solution.

products layer, and, thus, an increase in the localized current density; once the corrosion products layer is rebuilt, the current density decreases. Thus, the base alloy exhibited a high susceptibility towards a localized type of corrosion such as pitting. On the other hand, the time series for the AZ91E/TiC composite, Figure 8, showed transients of much lower intensity than those shown by the base alloy, indicating a lower susceptibility towards pitting corrosion. There is a factor called "Localization Index, LI," defined as

$$
\mathrm{LI}=\frac{\sigma_{i}}{i_{\mathrm{rms}}},
$$

where $\sigma_{i}$ is the current noise standard deviation and irms, the current root mean square value [17] which establishes that for LI values between 1 and 0.1 , the type of corrosion that the material suffers is localized; when the LI value lies between 0.1 and 0.01 , there is a mixture of both uniform and localized types of corrosion; finally, for LI values between 0.01 and 0.001 , there is a tendency towards a uniform type of corrosion. LI values for AZ91E base alloy and AZ91E/TiC composite were 0.78 and 0.2 , respectively. In view of these results, we can establish that both alloys have a tendency towards localized type of corrosion, being the base alloy more susceptible to this type of degradation. By using the potential noise standard deviation, $\sigma_{v}$, and dividing it over the current noise standard deviation, $\sigma_{i}$, we can obtain a noise resistance, $R_{n}$ and its change with time for the different steels is shown in Figure 9. This figure shows that $R_{n}$ decreased as time elapsed, in a similar way as that described by the polarization resistance value, $R_{p}$, shown on Figure 4 , and the charge transfer resistance on Figures 5 and 6 . The AZ91E base alloy exhibited lower $R_{n}$ values than those exhibited by the composite. Thus, if $R_{n}$ replaces $R_{p}$ in (2) we can see that the base alloy showed corrosion rates than the composite. Thus, by using any analysis tool, the composite showed a lower corrosion rate than the AZ91E base alloy.

SEM micrographs of corroded specimens are shown on Figure 10 together with X-ray analysis of corrosion products found on the composite. It can be seen that, on the AZ91E/TiC composite, some corroded particles can be found, detached from the matrix, which give as a result the transients in current as shown on Figure 7. Preferential attack along the matrix and the TiC particles interfaces can be seen due to a different electrochemical potential between the $\alpha$ $\mathrm{Mg}, \beta-\mathrm{Mg}$, AlMn inclusions, and $\mathrm{TiC}$ particles, that is, a galvanic effect. As evidenced by Tiwari et al. [14] who studied the corrosion behavior of two SiC Mg-based MMC, $\mathrm{Mg}$ $6 \mathrm{SiC}$, and $\mathrm{Mg}-16 \mathrm{SiC}$ (vol. \%) in aerated $1 \mathrm{M} \mathrm{NaCl}$ and found that the presence of $\mathrm{SiC}$ particles deteriorated the corrosion resistance of $\mathrm{Mg}$, and the corrosion resistance decreased with increasing $\mathrm{SiC}$ volume fraction. Thus, it is not expected that the corrosion rate of pure $\mathrm{Mg}$ decreases with the addition of $56 \mathrm{wt}$. \% of particles just because the contents of $\mathrm{Mg}$ is lower for the composite. The presence of $\mathrm{TiC}$ particles together with the presence of different phases with different electrochemical potential values, induce the presence of microgalvanic cells where the $\mathrm{TiC}$ and Al12Mg17 particles act as cathodes, whereas $\alpha$-Mg acts as anode, accelerating, thus, the corrosion rate of the later.

On the other hand, the corroded surface of the AZ91E base alloy showed porous, cracked layer of corrosion products, which do not allow the electrolyte to have access to the metal and give rise to the transients shown on Figure 8 . On the other hand, $\mathrm{X}$-ray data shows that the main corrosion products were $\mathrm{Mg}(\mathrm{OH})_{2}$ together with some $\mathrm{TiC}$ particles. This can be due to the fact that the presence of cathodic phases, such as the Al12Mg17 particles shown on Figure 1, during the alloy/composite formation enhances the susceptibility of hydrolysis reaction. Once hydrolysis reaction starts, corrosion reaction can proceed by oxidation of $\mathrm{Mg}$ as $\mathrm{Mg}^{2+}$ resulting in the formation of $\mathrm{Mg}(\mathrm{OH})_{2}$ as follows:

$$
\mathrm{Mg}^{2+}+2\left(\mathrm{OH}^{-}\right) \longrightarrow 2 \mathrm{Mg}(\mathrm{OH})
$$

The $\mathrm{Mg}^{2+}$ ions generate after oxidation of $\mathrm{Mg}\left(\mathrm{Mg} \rightarrow \mathrm{Mg}^{2+}\right)$, while $\mathrm{OH}^{-}$releases after oxygen reduction:

$$
2 \mathrm{H}_{2} \mathrm{O}+\mathrm{O}_{2}+4 \mathrm{e}^{-} \longrightarrow 4 \mathrm{OH}^{-} \text {. }
$$

This reaction explains the reason why $\mathrm{Mg}$ is not detected on the corrosion products because it is as $\mathrm{Mg}(\mathrm{OH})_{2}$. Because of insolubility of $\mathrm{Mg}(\mathrm{OH})_{2}$ in the solution it accumulates 

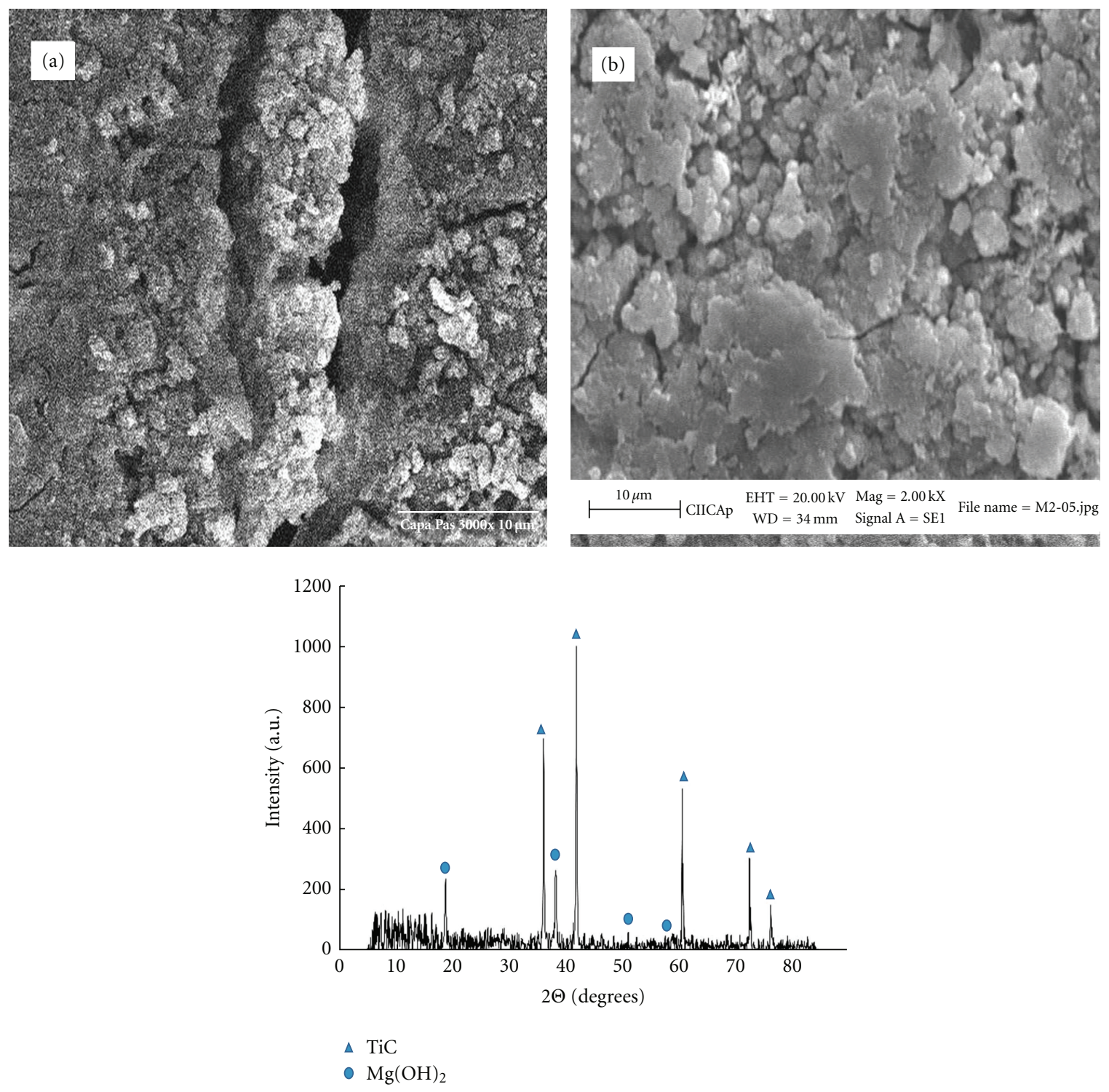

(c)

Figure 10: SEM micrograph of corroded (a) AZ91E/TiC composite and (b) AZ91E base alloy, and (c) X-ray diffractogram of corrosion products in the composite.

at the metal/solution interfaces of the electrode resulting in the formation of corrosion products layer, leaving inside it the uncorroded $\mathrm{TiC}$ particles found in the X-ray pattern. Formation of $\mathrm{Mg}(\mathrm{OH})_{2}$ with the increase of potential in the anodic region and their subsequent accumulation at the electrode interfaces seems to be the main reason for the occurrence of the diffusion limiting behaviour in the anodic region of the base alloy and composite polarization curves observed on Figure 2.

Electrochemical noise measurements have shown that both the base alloy and composite were susceptible to pitting corrosion, due to chloride ions adsorption, although the diffusion phenomena is less pronounced in the base alloy. The mechanism of pitting initiation involves three steps: (i) adsorption and penetration of chloride ions on the oxide surface, (ii) formation of a soluble hydroxychloride aluminium salts, and (iii) dissolution of the oxide where the film is thinner. Since adsorption of chloride ions is the first step of localized attack, it may therefore be inferred that susceptibility to pitting corrosion is likely to be more pronounced for a composite than for a base alloy. It has been reported [18-20] that the corrosion resistance of composites is less than their $\mathrm{Mg}$ alloys because the reinforcement/interface acts as potential sites for pitting corrosion. On the contrary, the corrosion resistance of composites has been reported to be higher than that for their alloys [21-23]. It was explained that as though pits were formed, their growth was restricted by the presence of particles and effective area offered by the matrix for corrosion to take place with reduced rate. We could observe this behaviour on this 
work; the pitting corrosion susceptibility of the composite was lower than that for the base alloy. In other works [24, 25] it has been reported that the corrosion resistance of the base alloys remains unchanged by the reinforcement of the particles. However, a galvanic effect between the TiC particles and matrix that enhanced the composite corrosion rate was evident. In the present work, occurrence of inductive loops shown by Nyquist diagrams for the base alloy suggest the adsorption of corrosive chloride ions at their metal/solution interface, whereas for the composite the most important process is diffusion of aggressive ions through the corrosion products layer.

\section{Conclusions}

A research on the addition of $56 \mathrm{wt}$ \% TiC particles on the corrosion resistance of the EZ91E Mg-base alloy in 3.5\% $\mathrm{NaCl}$ solution has been carried out using different electrochemical techniques. All different techniques have shown that the addition of $\mathrm{TiC}$ particles decreased both the uniform corrosion rate of the base alloy and the resistance towards pitting type of corrosion. Some evidence of a galvanic effect between the matrix and the TiC particles was found. Both the base alloy and the composite showed a tendency towards pitting corrosion, although on the base alloy the adsorption of chloride ions seemed to the corrosion-controlling factor, whereas in the composite the diffusion of the aggressive ions was the rate controlling factor.

\section{References}

[1] C. A. Leon, V. H. Lopez, E. Bedolla, and R. A. L. Drew, "Wettability of TiC by commercial aluminum alloys," Journal of Materials Science, vol. 37, no. 16, pp. 3509-3514, 2002.

[2] A. Contreras, C. A. León, R. A. L. Drew, and E. Bedolla, "Wettability and spreading kinetics of $\mathrm{Al}$ and $\mathrm{Mg}$ on TiC," Scripta Materialia, vol. 48, no. 12, pp. 1625-1630, 2003.

[3] D. Muscat, K. Shanker, and R. A. L. Drew, "Al/TiC composites produced by melt infiltration," Materials Science and Technology, vol. 8, no. 11, pp. 971-976, 1992.

[4] A. Contreras, A. Albiter, and R. Pérez, "Microstructural properties of the $\mathrm{Al}-\mathrm{Mg} / \mathrm{TiC}$ composites obtained by infiltration techniques," Journal of Physics Condensed Matter, vol. 16, no. 22, pp. S2241-S2249, 2004.

[5] S. Candan, "An investigation on corrosion behaviour of pressure infiltrated $\mathrm{Al}-\mathrm{Mg}$ alloy/SiC composites," Corrosion Science, vol. 51, no. 6, pp. 1392-1398, 2009.

[6] S. Candan and E. Bilgic, "Corrosion behavior of Al-60 vol.\% $\mathrm{SiC}$ composites in $\mathrm{NaCl}$ solution," Materials Letters, vol. 58, no. 22-23, pp. 2787-2790, 2004.

[7] S. Candan, "Effect of SiC particle size on corrosion behavior of pressure infiltrated $\mathrm{Al}$ matrix composites in a $\mathrm{NaCl}$ solution," Materials Letters, vol. 58, no. 27-28, pp. 3601-3605, 2004.

[8] Z. Ahmad and B. J. Abdul Aleem, "Degradation of aluminum metal matrix composites in salt water and its control," Materials and Design, vol. 23, no. 2, pp. 173-180, 2002.

[9] C. Chen and F. Mansfeld, "Corrosion protection of an $\mathrm{Al}$ 6092/SiC metal matrix composite," Corrosion Science, vol. 39, no. 6, pp. 1075-1082, 1997.

[10] G. E. Kiourtsidis, S. M. Skolianos, and E. G. Pavlidou, "A study on pitting behaviour of AA2024/SiC(p) composites using the double cycle polarization technique," Corrosion Science, vol. 41, no. 6, pp. 1185-1203, 1999.

[11] A. Pardo, M. C. Merino, A. E. Coy, R. Arrabal, F. Viejo, and E. Matykina, "Corrosion behaviour of magnesium/aluminium alloys in 3.5 wt.\% NaCl," Corrosion Science, vol. 50, no. 3, pp. 823-834, 2008.

[12] C. A. Nunez-Lopez, P. Skeldon, G. E. Thompson, P. Lyon, H. Karimzadeh, and T. E. Wilks, "The corrosion behaviour of Mg alloy ZC71/SiCp metal matrix composite," Corrosion Science, vol. 37, no. 5, pp. 689-708, 1995.

[13] J. Suqiu, J. Shusheng, S. Guangping, and Y. Jun, "The corrosion behaviour of $\mathrm{Mg}$ alloy AZ91D/TiCp metal matrix composite," Materials Science Forum, vol. 488-489, pp. 705$708,2005$.

[14] S. Tiwari, R. Balasubramaniam, and M. Gupta, "Corrosion behavior of $\mathrm{SiC}$ reinforced magnesium composites," Corrosion Science, vol. 49, no. 2, pp. 711-725, 2007.

[15] S. A. Salman, R. Ichino, and M. Okido, "A Comparative electrochemical study of AZ31 and AZ91 magnesium alloys," International Journal of Corrosion. In press.

[16] S. Budruk Abhijeet, R. Balasubramaniam, and M. Gupta, "Corrosion behaviour of $\mathrm{Mg}-\mathrm{Cu}$ and $\mathrm{Mg}$-Mo composites in 3.5\% NaCl," Corrosion Science, vol. 50, no. 9, pp. 2423-2428, 2008.

[17] H. H. Huang, W. T. Tsai, and J. T. Lee, "Electrochemical behavior of A516 carbon steel in solutions containing hydrogen sulfide," Corrosion, vol. 52, no. 9, pp. 708-716, 1996.

[18] O. P. Modi, M. Saxena, B. K. Prasad, A. H. Yegneswaran, and M. L. Vaidya, "Corrosion behaviour of squeeze-cast aluminium alloy-silicon carbide composites," Journal of Materials Science, vol. 27, no. 14, pp. 3897-3902, 1992.

[19] H. Y. Yao and R. Z. Zhu, "Interfacial preferential dissolution on silicon carbide particulate/aluminum composites," Corrosion, vol. 54, no. 7, pp. 499-507, 1998.

[20] M. S. N. Bhat, M. K. Surappa, and H. V. S. Nayak, "Corrosion behaviour of silicon carbide particle reinforced 6061/Al alloy composites," Journal of Materials Science, vol. 26, no. 18, pp. 4991-4996, 1991.

[21] S. J. Harris, B. Noble, and A. J. Trowsdale, "Corrosion behaviour of aluminium matrix composites containing silicon carbide particles," Materials Science Forum, vol. 217-222, no. 3, pp. 1571-1579, 1996.

[22] S. Y. Yu, H. Ishii, and T. H. Chuang, "Corrosive wear of $\mathrm{SiC}$ whisker- and particulate-reinforced 6061 aluminum alloy composites," Metallurgical and Materials Transactions A, vol. 27A, no. 9, pp. 2653-2662, 1996.

[23] E. P. Raju, K. Balakrishnan, and P. B. Shrinivasan, "Picolines as corrosion inhibitors for aluminium alloy in hydrochloric acid," Bulletin of Electrochemistry, vol. 13, pp. 107-113, 1970.

[24] L. Pinto and E. Zschech, "Mechanical properties and corrosion behavior of extrusions for aircraft applications made by discontinously silicon-carbide-reinforced aluminum matrix composites," Materials Science Forum, vol. 217-222, no. 3, pp. 1593-1598, 1996.

[25] H. Sun, E. Y. Koo, and H. G. Wheat, "Interfacial preferential dissolution on silicon carbide particulate/aluminum composites," Corrosion, vol. 47, no. 9, pp. 741-749, 1991. 

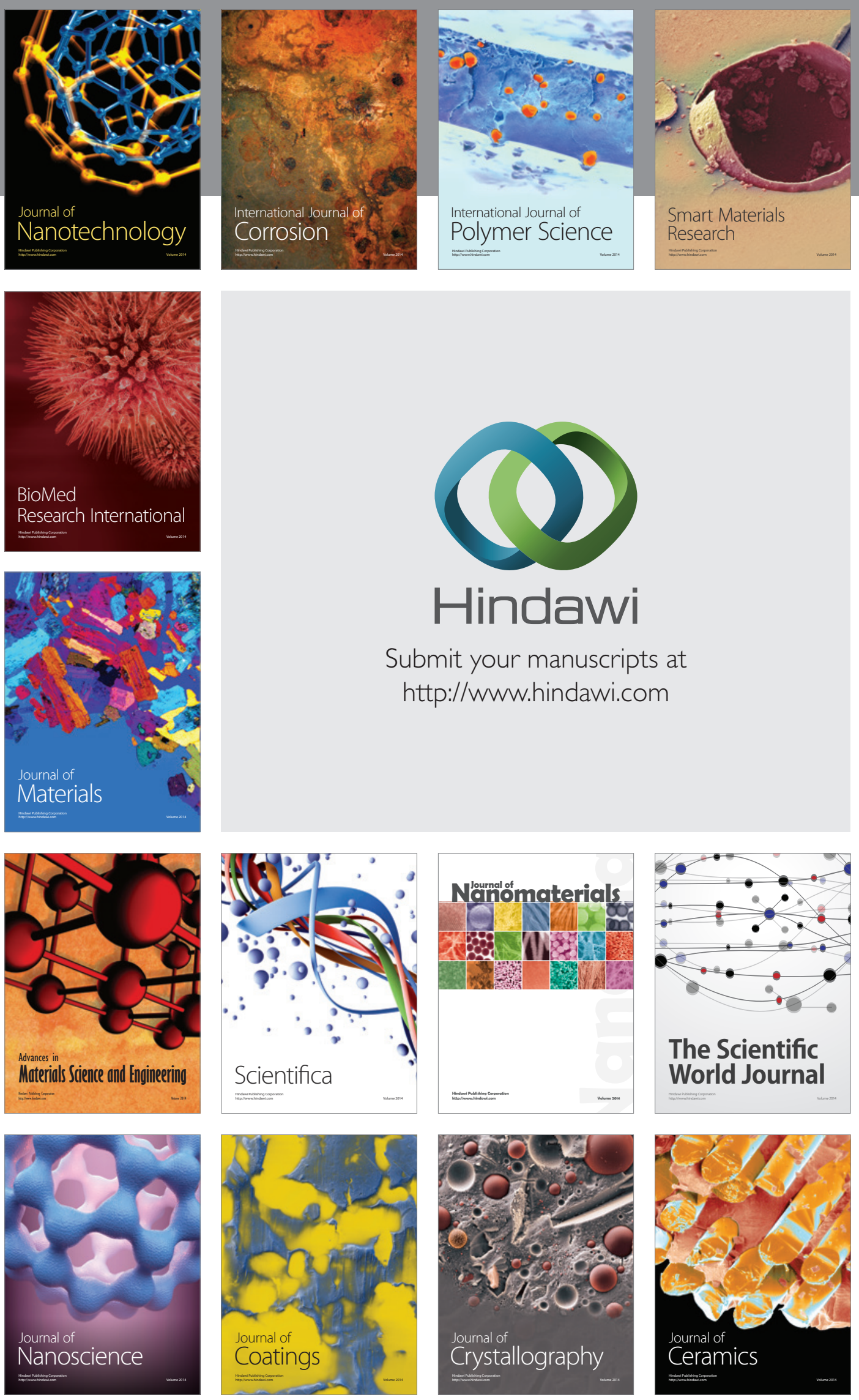

The Scientific World Journal

Submit your manuscripts at

http://www.hindawi.com

\section{World Journal}

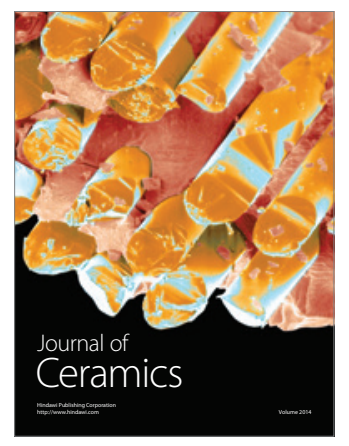

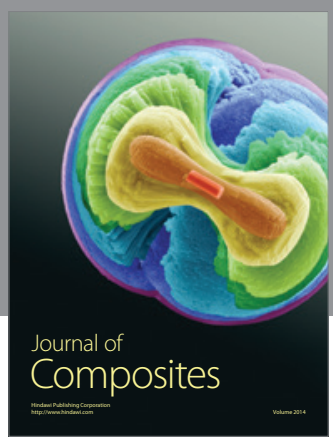
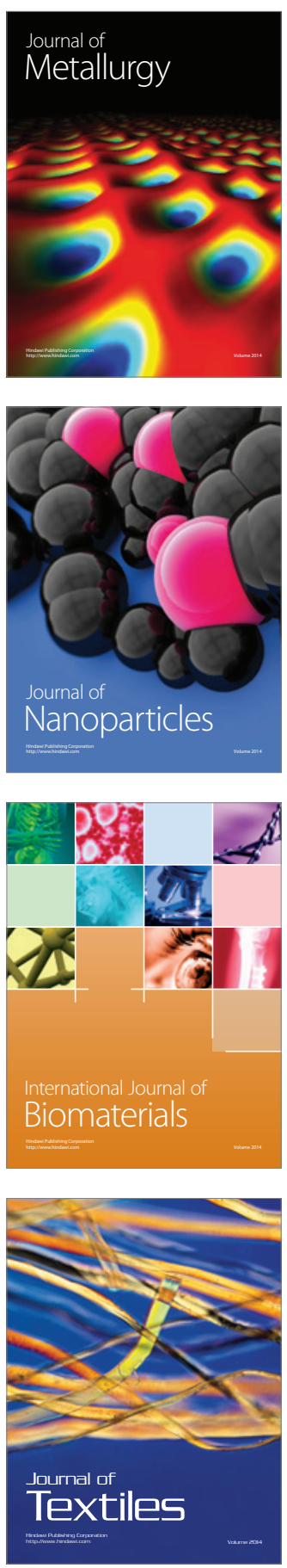